BEACH EROSION BOARD

OFFICE OF THE CHIEF OF ENGINEERS

\title{
GENERATION OF WIND WAVES OVER A SHALLOW BOTTOM
}

TECHNICAL MEMORANDUM NO. 51 


\section{GENERATION OF WIND WAVES OVER A SHALLOW BOTTOM}

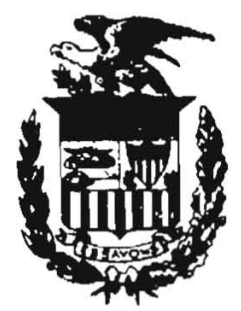

TECHNICAL MEMORANDUM NO.51

BEACH EROSION BOARD CORPS OF ENGINEERS 
FOREWORD

The prediction of wave characteristics in shallow water is of great importance along much of the Gulf coast of the United States, as well as for many inland water areas (as Lake Okeechobee, Florida). This has been difficult in the past as the effect of the shallow bottom is considerable, particularly in reducing the height from what would be expected by use of the deep water prediction methods.

This report presents a method for predicting the properties of waves generated in shallow water, obtained by a combination of the relationships for (deep water) ocean wave generation devised by Sverdmp and Munk and revised by Bretschneider, with the theory of wave energy losses in shallow water devised by Putnam and Johnson and revised by Bretschneider and Reid.

This report was prepared at the Agriculture \& Mechanical College of Texas in pursuance of Contract DA-49-055-eng-18 with the Beach Erosion Board, which provides in part for research and investigation of the properties of waves in shallow water. The author, C. L. Bretschneider, is a Research Engineer at the institution.

Views and conclusions stated in the report are not necessarily those of the Beach Erosion Board.

This report is published under authority of Public Law 166, 79th Congress, approved July 31, 1945. 
TABLE OF CONTENTS

Page

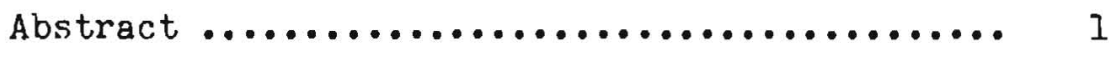

Introduction $\ldots \ldots \ldots \ldots \ldots \ldots \ldots \ldots \ldots \ldots \ldots \ldots$

Gase I - Generation of Wind Waves Over a

Bottom of Constant Depth ................ 3

Case II - Generation of Wind Waves Over a

Bottom of Constant Slope................ Il

Case III - Genera. - Generation of Wind Waves

Over a Variable Bottom Slope ............. 20

Summary and Conclusions $\ldots \ldots \ldots \ldots \ldots \ldots \ldots \ldots . . . . .21$

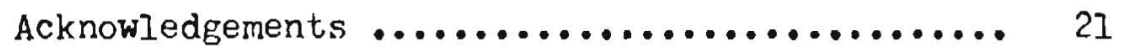

List of References $\ldots \ldots \ldots \ldots \ldots \ldots \ldots \ldots \ldots . \ldots \ldots$ 


\section{LIST OF SYMBOIS}

$C=$ propogational speed of a wave

$\mathrm{C}_{\mathrm{g}}=$ wave group velocity

$\mathrm{d}=$ mean water depth

$d_{F}=$ depth of water at end of Fetch

$f=$ bottom friction factor (dimensionless)

$F=$ fetch length of wind

$g=$ acceleration of gravity

$\mathrm{H}=$ wave height (vertical distance from trough to crest)

Ho = deep water significant wave height

$\mathrm{Ho}^{\prime}=$ equivalent deep water significant wave height

$\mathrm{K}_{\mathrm{g}}=$ wave shoaling factor $=\mathrm{H} / \mathrm{Ho}^{\prime}$ from Tables by Wlegel (7)

$L=$ wave length (horizontal distance between crests)

$m=$ bottom slope, vertical change per horizontal distance in direction of wave travel

$p=$ permeability coefficient, $\mathrm{ft}^{2}$

$t=$ time

$\mathrm{T}=$ wave period (time interval between passage of successive crests at a fixed point)

$U=$ wind speed

$x=$ horizontal distance in direction of wave travel

$\Delta x=$ increment of horizontal distance of wave travel or fetch length

8 - differential symbol

$\pi=3.1416$

$\nu=$ kinematic viscosity of fluid

$\phi_{f}=$ bottom friction dissipation function

$\phi_{p}=$ percolation dissipation function 
GENERATION OF WIND WAVES OVER A SHALLOW BOTTOM

BY

Charles L. Bretschneider

The Agricultural and Mechanical College of Texas

Abstract. A numerical method is presented in this report for determining the generation of wind waves over a shallow bottom, taking bottom friction and percolation in the permeable bea bottom into account. To date as far as the author knows, there has been no single theoretical development for determining the actual growth of waves generated by winds blowing over relatively shallow water. The numerical method presented in this report is essentially that of successive approximations wherein wave energy is added due to wind stress and subtracted due to bottom friction and percolation. This is done by making use of the deep water forecasting relationships originally developed by Sverdrup and Munk (6)* and revised by Bretschneider (2) for determining the energy added due to wind stress. The amount of wave energy loss due to bottom friction and percolation is determined from the relationships developed by Bretschneider and Reid (3). The resultant wave heights and periods are obtained by combining the above relationships by numerical methods.

The basic assumptions applicable to the development of the deep water wave generation relationships (2) as well as the development of the relationships for bottom friction loss (4) and percolation loss (5) apply to the development in this report. For a detailed discussion of these basic assumptions, the reader is referred to the list of references at the end of this report.

Empirical data on wind generated waves in shallow water obtained from the Gulf of Mexico will be presented in a separate technical report at a later date. Although there are insufficient wave data to date to verify completely all relationships presented in this report, it is believed that the method will prove satisfactory once sufficient wave data become available to enable accurate evaluation of the constants.

Introduction. The prediction of wave heights and periods was practically an unknown art prior to World War II. In planning large scale amphibious landings during the war, it was a major concern to have advance information on wave conditions. This problem was first attacked by Sverdmup and Munk (6) who combined observed wave data with the classical equations of hydrodynamics to develop the semi-empirical relationships which govern deep water wave generation and decay. These were subsequently revised by Arthur (I) as additional wave observations were collected, and again by Bretschneider (2).

* Numbers in parentheses refer to list at end of report. 
Usj.ng the above mentioned relationships it is possible to forecast or hindcast deep water wind waves and swell. The general procedure becomes relatively simple, once the necessary meteorological information is available.

The problem of forecasting or hindcasting wind waves in shallow or intermediate water depths, however, is more complex than that of deep water wind waves, since the water depth and type of bottom limits the rate of growth of the waves. The prediction of wind waves generated in shallow water is indeed a problem in the Gulf of Mexico. The approach given in this report is a first attempt at developing a method for predicting such waves.

In many cases, such as storms generating waves off the continental shelf in the Gulf of Mexico, the waves may originally generate as deep water waves. As the waves continue to advance shoreward (under the same wind system (further development may be in the shallow water, where the water depth is equal to or less than one-half the wave length. Further generation shoreward will continue until the rate at which the wind is adding energy to the waves is equal to the rate at which energy is lost from the waves by bottom friction and percolation in the permeable sea bottom. This is known as the steady state condition at that particular depth. Furthermore, if the waves continue to advance upslope (under the same wind system) a greater amount of energy will be lost due to bottom friction and percolation in the permeable sea bottom than is gained through wind stress. This will result in an actual attenuation in wave height, even though the original wind system remains constant over the area of question.

Storm waves generated by strong winds over deep water may be of considerable magnitude, and the resulting swell will advance for hundreds of ililes shoreward. As the swell advances over a shallow bottom, a considerable amount of wave energy may be lost due to bottom friction and percolation in a permeable sea bottom. Putnam and Johnson ( 4 ) have developed a dissipation function for bottom friction and Putnam (5) presents a dissifation function for percolation in a permeable sea bottom.

Using the above mentioned dissipation functions, Bretschneider and Reid (3) have obtained a number of solutions and present a number of nomographs for determining the change in wave height (or the change in wave energy) due to bottom friction, percolation and refraction, for swell traveling over a shallow bottom. Consequently an independent method (2) exists by which it is possible to determine the deep water wave energy during any stage of generation as a function of wind speed, wind duration and fetch length. Also an independent method (3) exists by which it is possible to determine the wave energy loss due to bottom friction and percolation in a permeable sea bottom. To date as far as the author knows, there has been no single theoretical development for determining the resultant of the above mentioned effects. Because of the number of variables involved a direct mathematical investigation of the problems of wave generation over a shallow bottom would be very complicated. 
The method of obtaining relationships for the generation of wind waves in shallow water by use of numerical methods foljows:

Case I: Generation of Wind Waves Over a Bottom of Constant jepth.

If $\mathrm{d} / \mathrm{T}^{2}<2.5 \mathrm{ft} / \mathrm{sec}^{2}$ then the waves effectively "Feel bottom" ank the depth and botton conditions enter as additional factors with respect to the heights and period of waves which can be generated. The effect of frictional dissipation of energy at the bottom for such waves limits the rate of wave generation and also places an upper limit on the wave heights which can be gentrated by a given wind speed and fetch length.

The following expression for the reduction in height of waves traveling over an impermeable bottom of constant depth without refraction is obtained from reference ( 3 ).

$$
\left.H=H_{I}\left[\frac{\mathrm{fH}_{1} \phi_{\mathrm{f}} \Delta \mathrm{x}}{\mathrm{r}_{\mathrm{s}} \mathrm{T}^{4}}+1\right]\right]^{-1}
$$

where $H=$ the final significant height at $x$,

$$
\begin{aligned}
& \mathrm{H}_{1}=\text { original significant height at } \mathrm{x}=\mathrm{x}_{1} \text {, } \\
& \Delta x=x-x_{1} \text {, the horizontal distance of wave travel in feet, } \\
& f=\text { friction factor (dimensionless), a characteristic of the bottom, } \\
& T=\text { wave period in seconds } \\
& K_{s}=\left[\left(\tanh \frac{2 \pi d}{I}\right)\left(1+\frac{4 \pi d / I}{\sinh 4 \pi d / I}\right)\right]^{-\frac{1}{2}}
\end{aligned}
$$

a dimensionless shoaling factor, given as $\mathrm{H} / \mathrm{H}_{\mathrm{O}}{ }^{\prime}$ in tables by wiegel (7)

$$
\phi_{f}=\frac{64 \pi^{3}}{3 g^{2}}\left[\frac{k_{s}}{\sinh 2 \pi d / 1}\right]^{3}, \sec ^{4} \mathrm{ft}^{-2},
$$

$d=$ depth of water in feet

$I=\frac{g}{2 \pi} \quad T^{2}(\tan 2 \pi \mathrm{d} / \mathrm{L})$, wave length in feet

$g=$ acceleration of gravity in feet/sec. ${ }^{2}$

Equations 1,2 and 3 are based on considerations of waves of small steepness and therefore represent only an approximation for waves near the maximum steepness. The quantity $\left(\phi_{f} / K_{s}\right)\left(d / T^{2}\right)^{2}$ versus $d / T^{2}$ is presented graphically in Figure 2.

Figure 1, the Fetch Graph for deep water wave generation, in effect represents the generation of wave energy in deep water as a function of $\frac{\mathrm{gF}}{\mathrm{U}^{2}}$ 


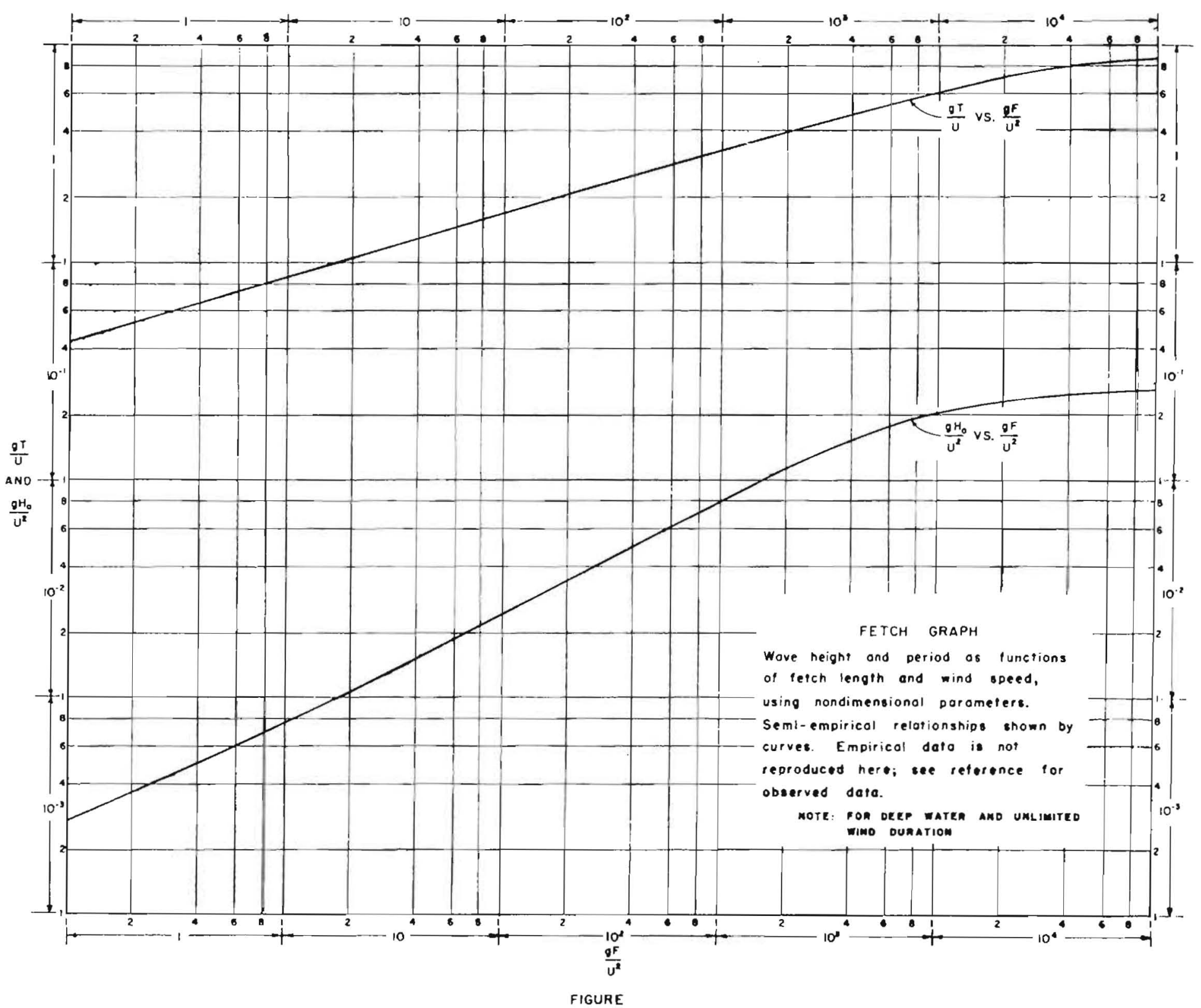


or

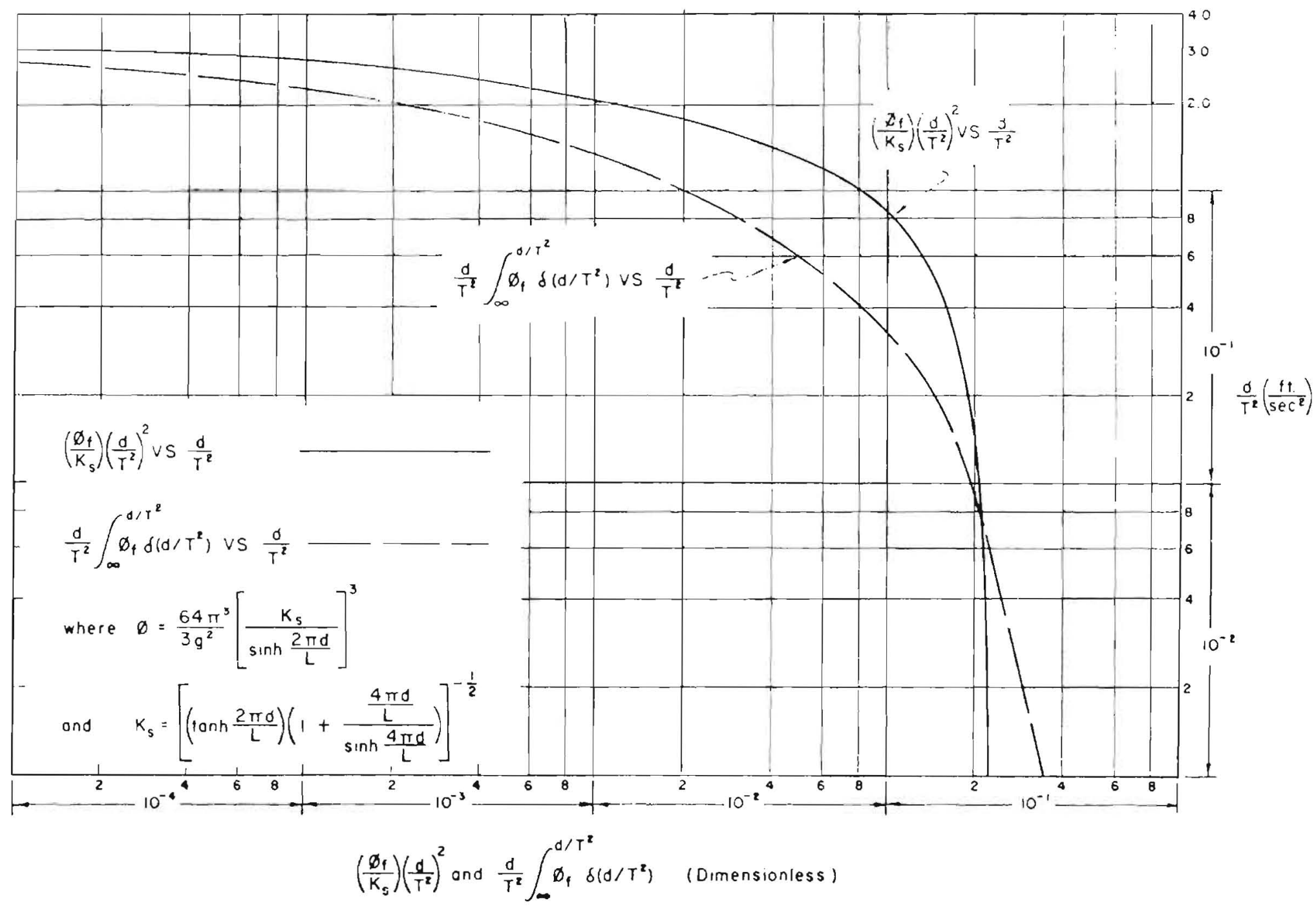

FIGURE 2 
and $t U / F$, whereas equation 1 represents the dissipation of wave energy due to bottom friction. Figure $I$ and equation $l$ were combined by a numerical method of successive approximation to obtain relationships for the generation of waves over an impermeable bot tom of constant depth. The procedure was as follows. Figure 1 was used to gencrate the waves over an increment of fetch, $\Delta x$, then equation 1 was used to determine the actual wave height at the end of $\Delta x$, taking energy loss due to bottom friction into account. Using the new wave height determined by equation 1 , an equivalent deep water fetch length was determined from Figure 1. Then a new fetch length, equal to the above equivalent deep water fetch length plus an increment $\Delta x$ was used to determine a new deep water wave height and period. Equation 1 again was used to determine the wave height at the end of the second section. The wave period for each section $\Delta \mathrm{x}$ used in equation $I$ was taken as the average of the wave period at the end of the equivalent deep water fetch length and the end of the increment $\Delta x$, and was determined from Figure 1. The numerical process of successive approximations, for a given value of $U$ and $d$, was carried to the point where the values of $H$ remained constant, that is the steady state condition for the generation of wind waves over an impermeable bottom of constant depth.

The above method of determining the shallow water generation was applied to 16 conditions, of a range in wind speed from 25 to 120 miles per hour, and depths from 10 to 200 feet for $f=0.01$. Each set of computations involved from 7 to 17 increments of $\Delta x$.

Using the steady state conditions, dimensionless relationships of $\mathrm{gH} / \mathrm{U}^{2}$ and $\mathrm{gT} / \mathrm{U}$ versus $\mathrm{gd} / \mathrm{U}^{2}$ for $\mathrm{f}=\mathrm{Dl}$ were developed. Data of wind waves generated in shallow water of Lake Okeechobee presented in other reports $(8,9,10)$ indicate that the steady state wave height corresponds best with a bottom friction factor of $f=.01$. The observed wave periods, however, were slightly higher than the computed wave period as determined by the above method. This is to be expected,since the assumption of energy partition between the wave height and the wave velocity is not necessarily the same in shallow water as in deep water. Consequently the above (first) computations represent only the first approximation. The relationship of $\mathrm{gT} / \mathrm{U}$ versus $\mathrm{gd} / \mathrm{U}^{2}$ was revised to fit the observed wave data and the second approximation of $\mathrm{gH} / \mathrm{U}^{2}$ versus $\mathrm{gd} / \mathrm{U}^{2}$ determined by using the above period relationships instead of the deep water wave period relationship given by Figure 1. The revised computations showed that corrections of about -2 percent at $\mathrm{gd} / \mathrm{U}^{2}=.01$ and -1 percent at $\mathrm{gd} / \mathrm{U}^{2}$ $=0.1$ were required for the corresponding $\mathrm{gH} / \mathrm{U}^{2}$ values. The above correction is small, for in shallow water the rate at which energy is dissipated by bottom friction becomes less and less dependent on the wave period. In fact for $\mathrm{d} / \mathrm{T}^{2} ₹ 0.1$, the dissipation of wave energy by bot tom friction becomes dependent entirely on the wave height, water depth, and bottom friction factor.

Figure 3 shows the generation curves for a bottom of constant depth for wind speeds of 25,50 , and 100 miles per hour, and bottom friction factor
$=0.01$. 

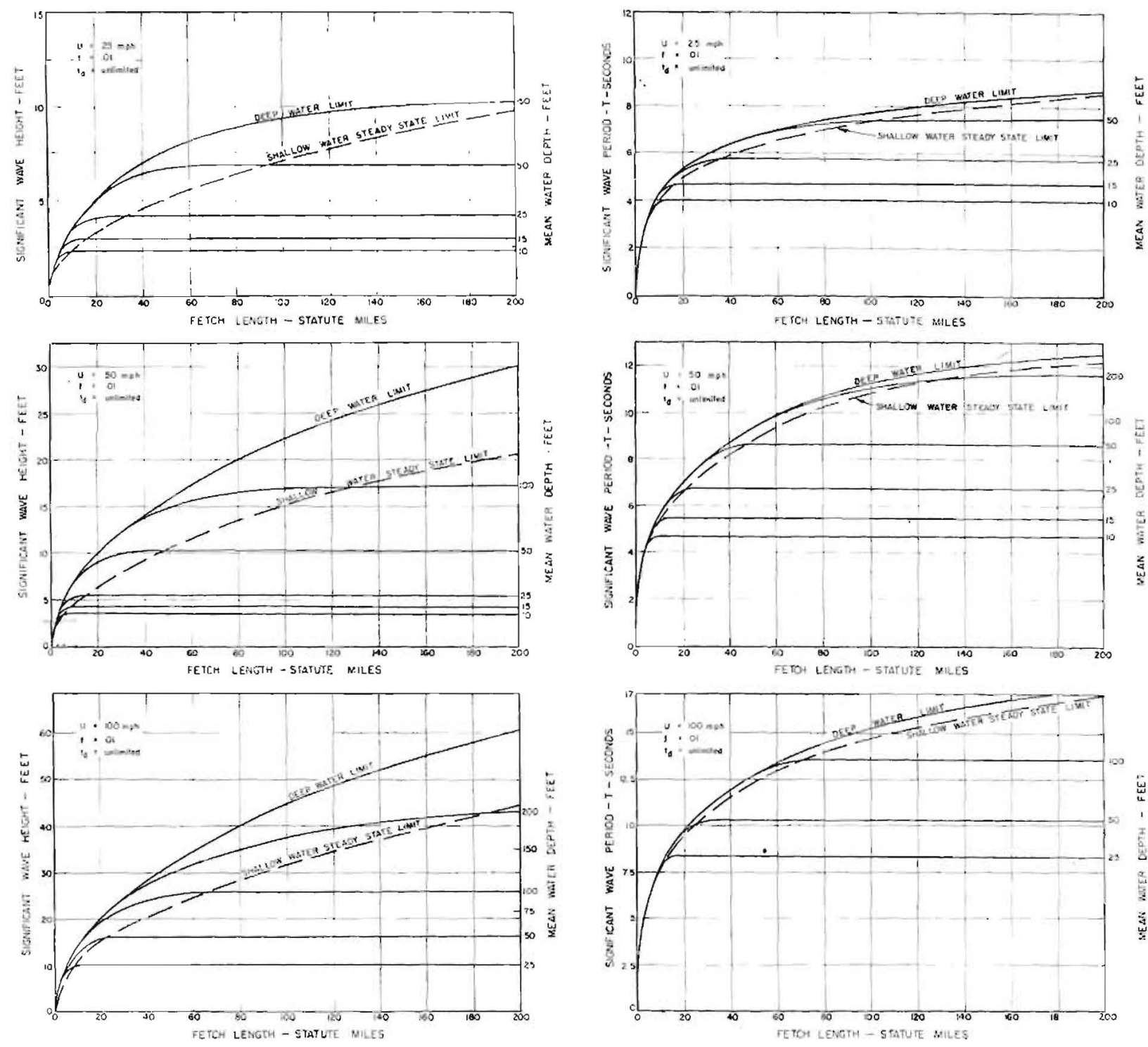

GENERATION OF WIND WAVES OVER A BOTTOM OF CONSTANT OEPTH

FIGURE 3 
Using the generation curves of Figure 3, Figures 4 and 5 were developed. Figure 4 presents the generation of wave height in dimensionless form as $\mathrm{gH} / \mathrm{U}^{2}$ versus $\mathrm{gd} / \mathrm{U}^{2}$ and $\mathrm{gF} / \mathrm{U}^{2}$ for $\mathrm{f}=.01$. From Figure 4 , it is possible to determine wave generation for wide ranges of wind speeds, mean water depth, and fetch lengths, for the special case of an impermeable flat bottom having a friction factor $\mathrm{f}=.01$.

Figure 5, Constant Depth Graph, for unlimited fetch length and wind duration presents the steady state relationships of $\mathrm{gH} / \mathrm{U}^{2}, \mathrm{gT} / \mathrm{U}, \mathrm{C}_{\mathrm{g}} / \mathrm{U}$, $\mathrm{H} / \mathrm{L}, \mathrm{g} \mathrm{t}_{\mathrm{min}} / \mathrm{U}$, and $\mathrm{F}_{\mathrm{min}} / U t_{\min }$, as functions of $\mathrm{gd} / \mathrm{U}^{2}$, for $\mathrm{f}=.01$.

Values of the wave length $L$ and the group velocity $C_{g}$, respectively, were determined from Figures 3 and the following equations:

$$
\begin{aligned}
& L=\frac{g T^{2}}{2 \pi} \tanh \frac{2 \pi d}{L} \\
& C_{g}=\frac{L}{2 T}\left[1+\frac{\frac{4 \pi d}{L}}{\sinh \frac{4 \pi d}{L}}\right]
\end{aligned}
$$

The minimum duration, $t_{\text {min }}$ was determined by graphical integration from the following expression

$$
\int_{0}^{t} d t=\int_{0}^{F} \frac{1}{c_{g}} d x
$$

The relationships given in Figures 3,4 and 5 apply only to the generation of wind waves over an impermeable sea bottom of constant depth for $f=0.01$. Similar relationships could be developed for other friction factors.

Not only may the friction factor be different from $f=0.01$ but the bottom may not be impermeable. The following expressions for the reauction in height of waves travelling over a permeable sea bottom of constant depth (neglecting bottom friction and refraction) is obtained from reference (3)

$$
H=H_{I} \exp \frac{-\phi_{p} \Delta x \quad p}{\mathrm{~T}^{3} v}
$$

where

$$
\mathrm{p}=\text { permeability coefficient, } f t^{2}
$$

$$
\begin{aligned}
\phi_{\mathrm{p}} & =\frac{64 \pi^{3} \mathrm{Ks} \mathrm{s}^{2}}{\mathrm{~g} \sinh \frac{4 \pi \mathrm{d}}{\mathrm{L}}} \mathrm{sec}^{2} \mathrm{ft}^{-1} \\
v & =\text { kinematic viscosity } \mathrm{ft}^{2} \mathrm{sec}^{-1} \\
\mathrm{e} & =\text { base of natural logarithm. }
\end{aligned}
$$




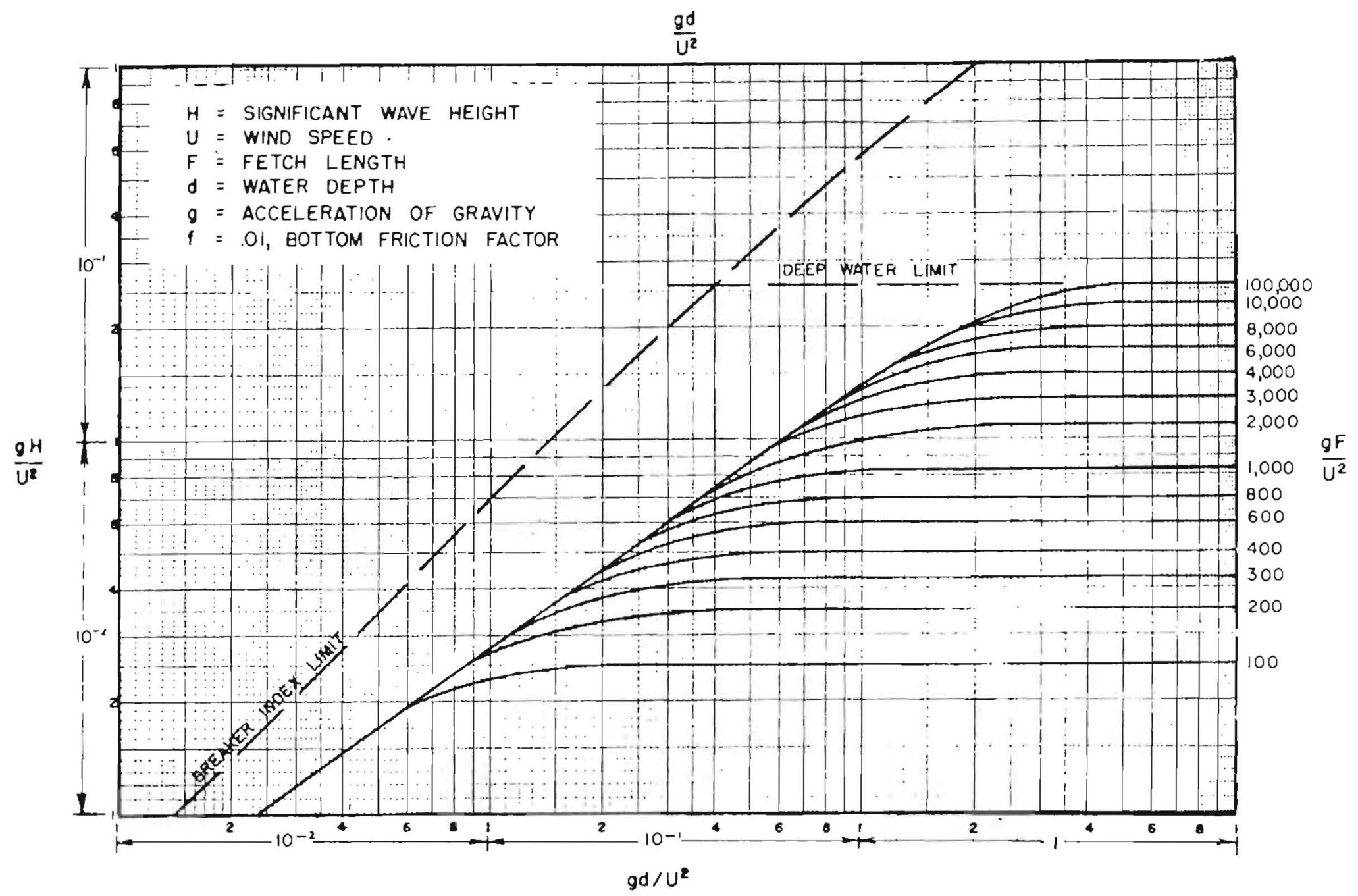

GENERATION OF WIND WAVES OVER A BOTTOM OF CONSTANT DEPTH FOR UNLIMITED WIND DURATION PRESENTED AS DIMENSIONLESS PARAMETERS 


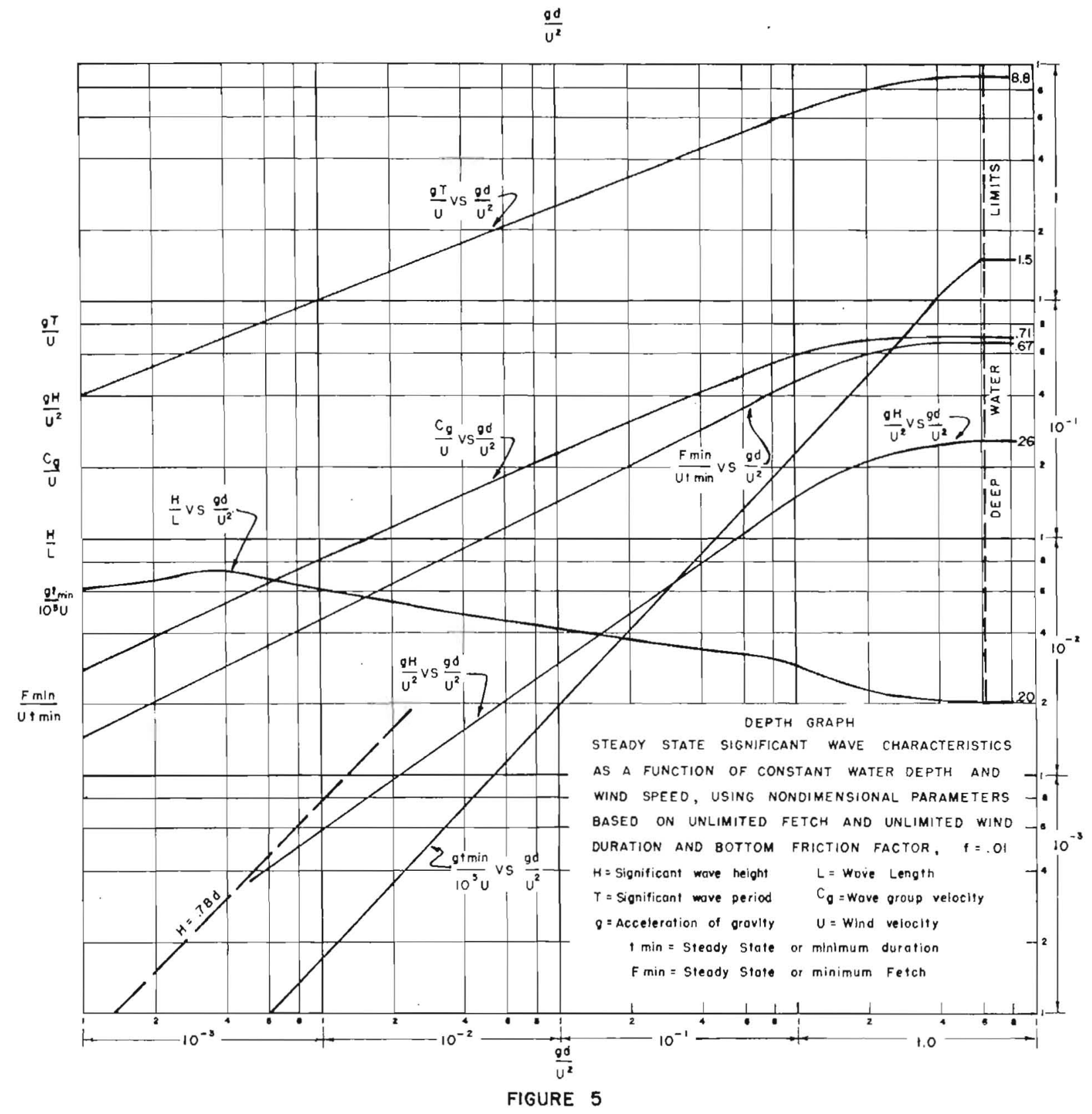


The other symbols are the same as in equation 1.

In case of percolation losses one could determine by the numerical method of successive approximation, relationships for the generation of wind waves over a permeable sea bottom. The combined effect of bottom friction and percolation in a permeable sea bottom on the generation of wind waves can be handled in a similar manner.

Case II: Generation of Wind Waves Over a Bot tom of Constant Slope.

The special case of wind generated waves over a shallow bot tom of constant depth occurs not so frequently as the case of generation over a bottom of variable depth. This is particularly true for wind waves generated in the Gulf of Mexico. The wind waves may be generated in deep water in the Gulf of Mexico, but as the storm waves move upslope shoreward under the continued influence of the wind further generation must take into account the effect of bottom friction and percolation in the permeable sea bottom, the factors of which retard the rate of generation. In fact in the more shallow regions the rate of generation may be less than the rate of dissipation of wave energy and the actual wave heights and periods will decrease shoreward of deep water even though the original wind speed and direction remain constant.

This section of the report deals with the generation of wind waves over a bottom of constant slope, but the method is easily extended to a bottom of variable slope such as exists in the Gulf of Mexico. (See Case III).

In the place of equation 1 (for a bottom of constant depth) the following equation for an impermeable bottom of constant slope is obtained from reference (3)

$$
H=H_{0} K_{s}\left[\left[\frac{f H_{0}}{m T^{2}} \int_{\infty}^{d / T^{2}} \phi_{f} \delta\left(d / T^{2}\right)+1\right]\right]^{-1}
$$

where $H=$ significant wave height, in feet at a relative depth of $d / T^{2}$.

$\mathrm{H}_{\mathrm{O}}=$ initial deep water significant wave height, feet,

$m=$ bottom slope (change of depth per unit distance in the direction of wave travel).

The other factors are the same as in equation 1 . Equation 9 can be used together with Figure 1 to evaluate wave heights and periods over a bottom of constant slope by a similar process of successive approximations as was employed for a bottom of constant depth.

For reasons which become apparent in a later section of this report, equation 9 was used in the following form 


$$
H_{0}{ }^{\prime}=H_{0}\left[\left\lceil\frac{\mathrm{fH}_{0}}{m^{2}} \int_{\infty}^{\mathrm{d} / \mathrm{T}^{2}} \phi_{\mathrm{f}} \delta\left(\mathrm{d} / \mathrm{T}^{2}\right)+1\right]\right]^{-1}
$$

where Ho' is defined as the equivalent deep water significant wave height; that is the wave height which would exist in deep water if the wave height, $H$, in shallow water were unshoaled directly to deep water unaffected by refraction or energy loss. The actual wave height can then be determined from

$$
H=H^{\prime} K_{S}
$$

where $Y_{5}$ is equal to the shoaling factor and can be obtained from Tables by Wiegel (7) under the column H/Ho'.

Equation 10 and Figure $I$ were used to evaluate Ho' over a bottom of constant slope for a number of initial conditions. The integral involved in equation 9 has been evaluated by graphical integration and is presented in Figure 2, as

$$
d / T^{2} \int_{\infty}^{d / T^{2}} \phi_{f} \delta\left(d / T^{2}\right) \text { versus } d / T^{2} \text {. }
$$

A sumnary of the number of different sets of Computations of Wind Wave Generation Over a Bottom of Constant Slope is presented below (the numbers in the table indicate the number of individual initial deep water fetch lengths selected)

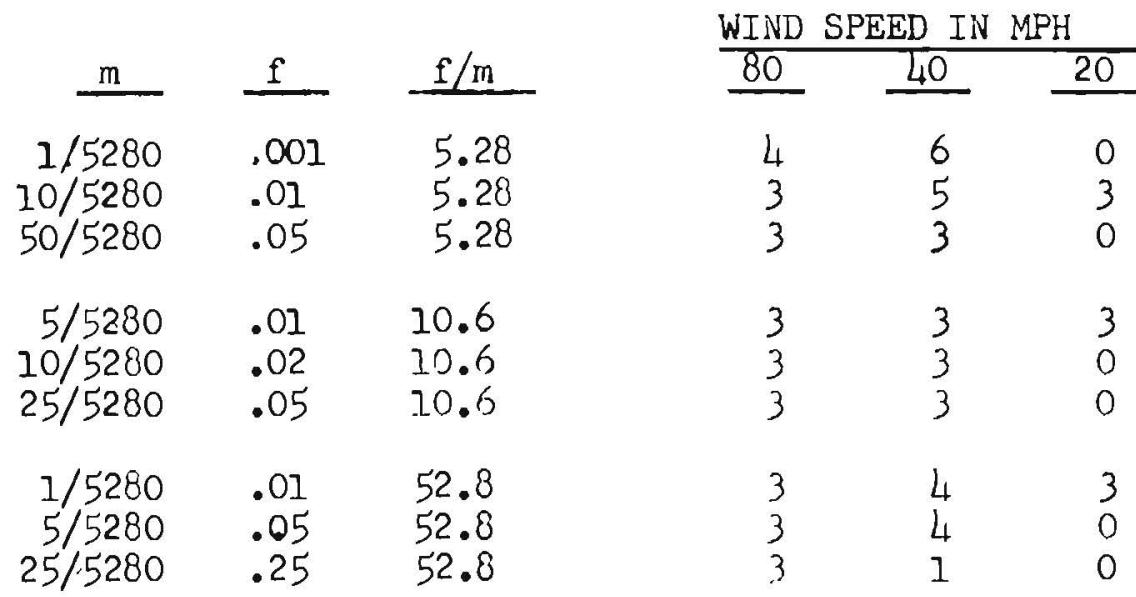

$m=$ bottom slope $=$ rise per horizontal distance.

$f=$ bottom friction factor.

Figures 6 and 7 are examples of the generation of wind waves over a bottom of constant slope for wind speeds of 40 and 80 miles per hour respectively and $f / m=10.6$ for various values of $f$ and $m$. The dashed lines are the actual generation lines, where the energy is being lost by 


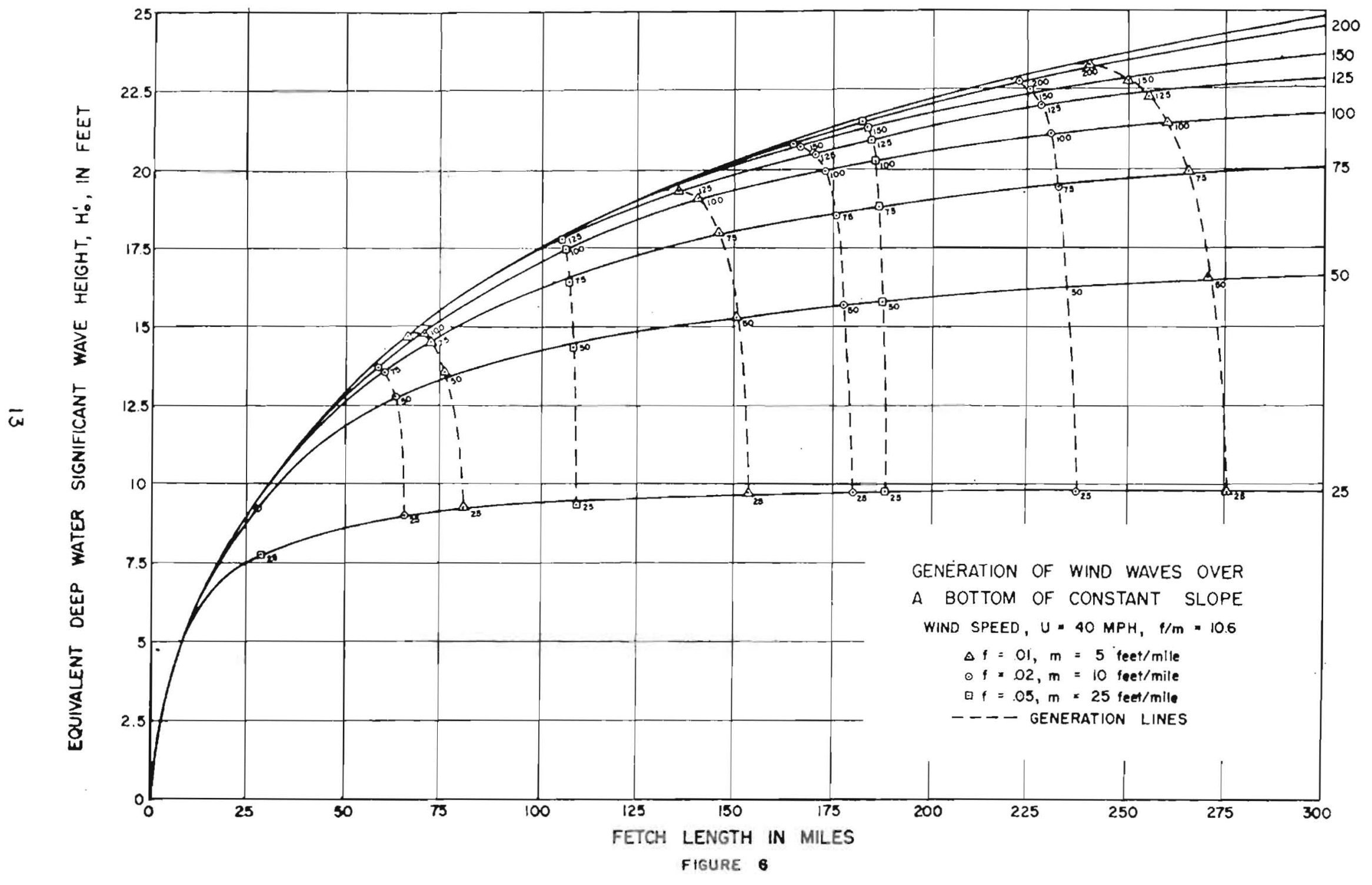

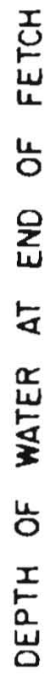




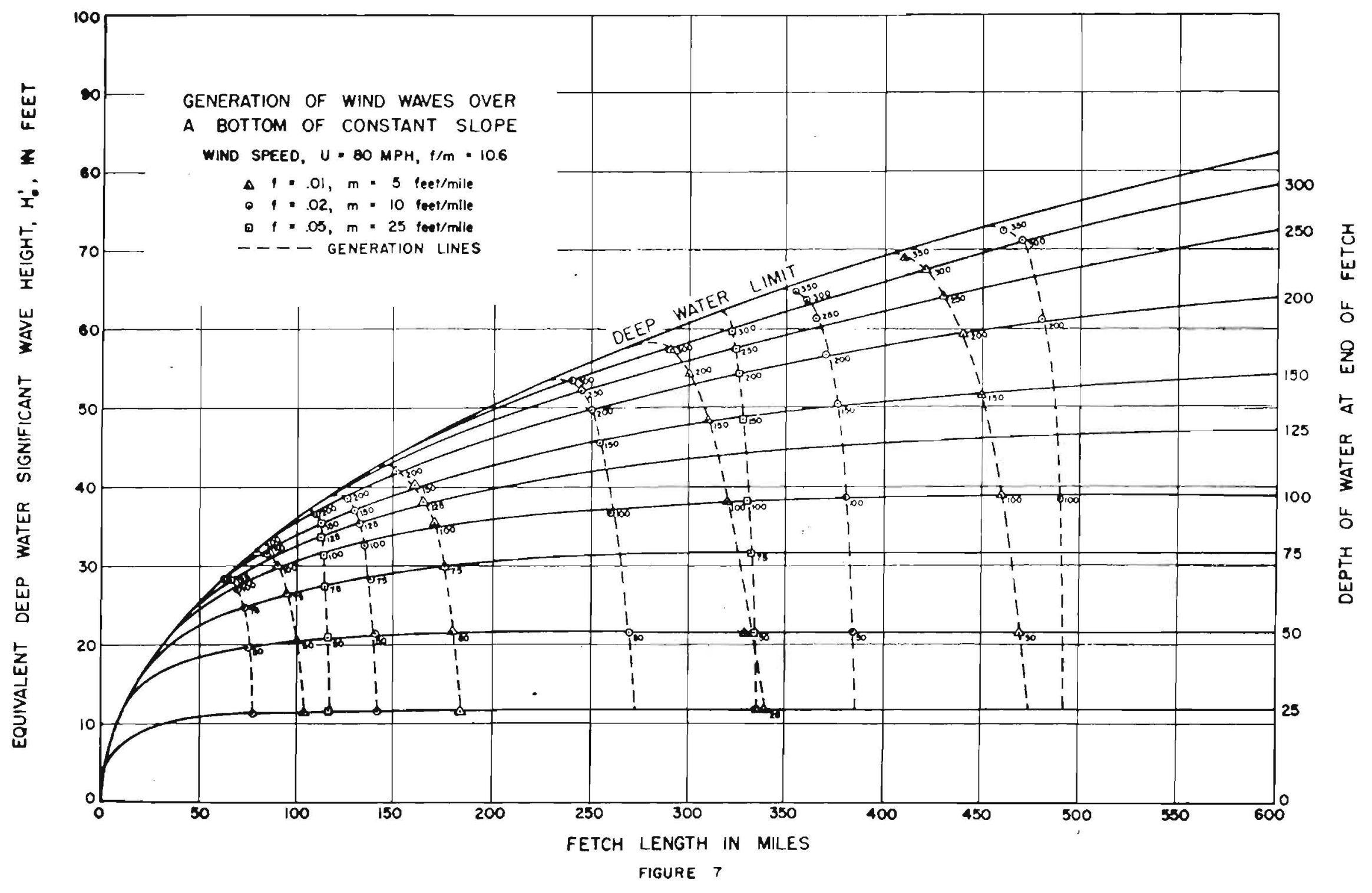


bottom friction at a more rapid rate than is being gained by wind stress. Isolines of constant depth at end of fetch (solid lines of Figure 7) were constructed through the generation lines. For any particular.wind speed and various combinations of $f$ and $m$ for $f / m=$ constant, it was found that the same set of isolines applied very nearly. The maximum deviations of the lines of constant depth at the end of the fetch for the extreme ranges of $f$ and $m$ used in the above computations were less than 1 percent for $\mathrm{f} / \mathrm{m}=5.28$, less than 3 percent for $\mathrm{f} / \mathrm{m}=10.6$ and 1 ess than $?$ percent for $\mathrm{f} / \mathrm{m}=52.8$.

From the above fairly-good agreement it was concluded that $\mathrm{f} / \mathrm{m}$ would be an excellent parameter for predicting wave heights over a bottom of constant slope.

Figure 8 presents the maximum values of $\mathrm{gH}_{\mathrm{O}} / \mathrm{U}^{2}$ versus $\mathrm{gdF} / \mathrm{U}^{2}$ for the three conditions of $\mathrm{f} / \mathrm{m}=5.28,10.6$ and 52.8 . It might be noted that the condition of $\mathrm{f} / \mathrm{m}=52.8$ corresponds very nearly to the condition of $f=0.01$ for a flat bottom as given in Figure 3. That is for $f=0.01$ and $\mathrm{f} / \mathrm{m}=52.8, \mathrm{~m}$ is equal to 1 foot rise per mile horizontal distance, which is very nearly a flat bottom.

Figures 9, 10 and 11 are dimensionless plots of $\mathrm{EH}^{1} / \mathrm{U}^{2}$ versus $\frac{\mathrm{gd}_{\mathrm{F}}}{\mathrm{U}^{2}}$ with $g F / \mathrm{U}^{2}$ as a parameter for $\mathrm{f} / \mathrm{m}=5.28,10.6$ and 52.8 respectively.

Unlike Figure 3 no relationships are presented for the wave period. The reason being that the equivalent deep water significant wave period

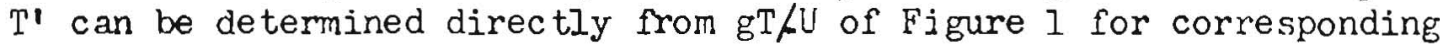
values of $\frac{\mathrm{gH}_{\mathrm{O}^{\prime}}}{\mathrm{U}^{2}}=\frac{\mathrm{gH}_{\mathrm{O}}}{\mathrm{U}^{2}} \cdot\left(\mathrm{T}^{\prime}=\mathrm{T}\right)$ is the s ame resulting wave period obtained by the numerical method of computations for corresponding values of $\left(\mathrm{H}_{\mathrm{O}}{ }^{\prime}=\mathrm{H}_{\mathrm{O}}\right)$. The above statement is more clearly understood by the following example:

Example 1

$$
\text { Given: } \begin{aligned}
F & =300 \mathrm{miles} \\
U & =50 \mathrm{mph}=73.5 \mathrm{ft} / \mathrm{sec} \\
\mathrm{m} & =10 \mathrm{ft} / \mathrm{mile} \\
f & =0.02 \\
d_{F} & =50 \text { feet }
\end{aligned}
$$

Solution:

$$
\begin{aligned}
\mathrm{f} / \mathrm{m} & =10.6 \frac{0.02}{10 / 7270} \\
\mathrm{gF} / \mathrm{U}^{2} & =\frac{322 \times 5280 \times 300}{(73.2)^{2}}=9450
\end{aligned}
$$




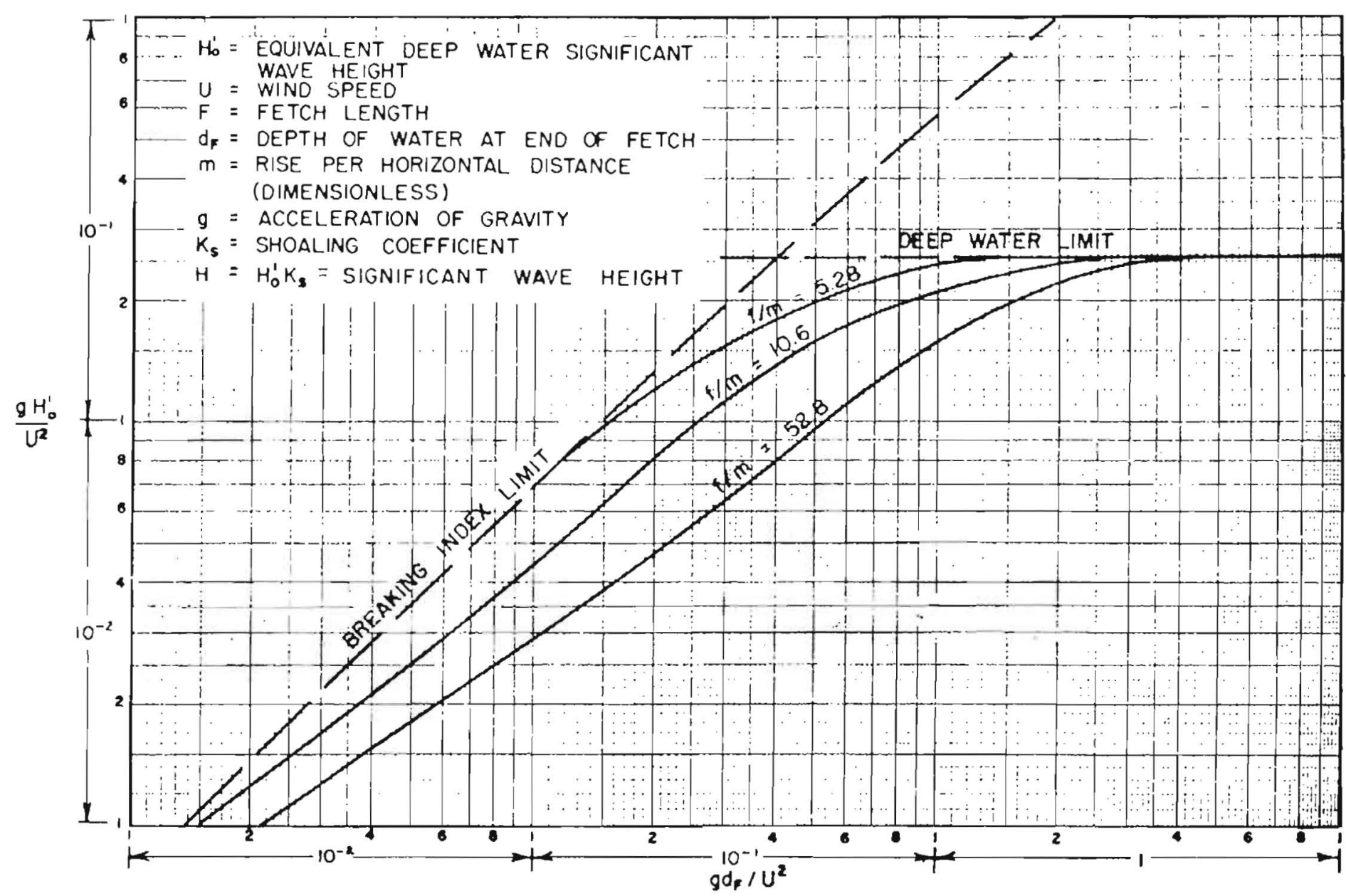

STEADY STATE GENERATION OF WIND WAVES OVER A BOTTOM OF CONSTANT SLOPE, $m$, FOR VARIOUS FRICTION FACTORS, $f$ NOTE: FOR UNLIMITED FETCH AND UNLIMITEO WIND DURATION 


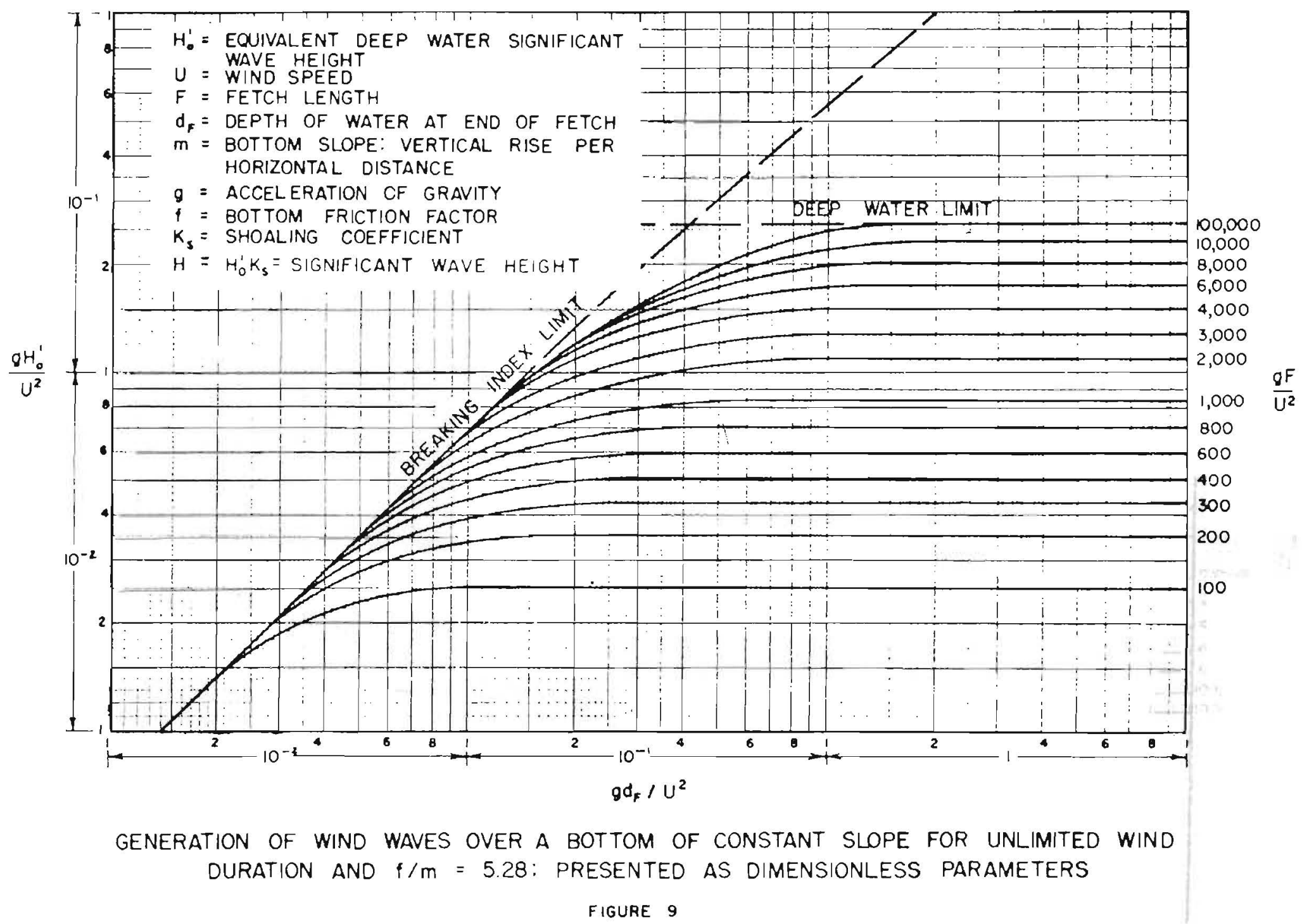




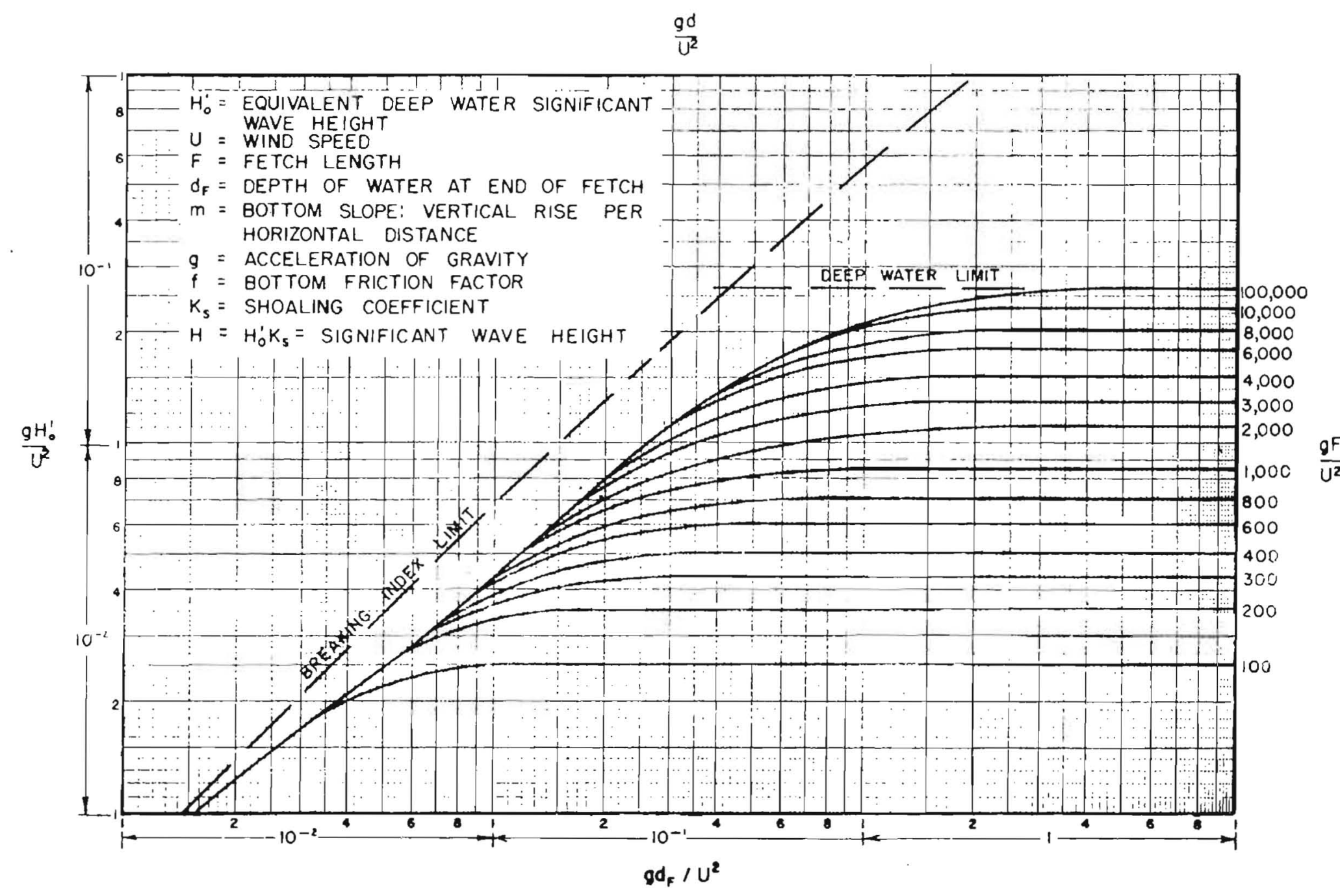

GENERATION OF WIND WAVES OVER A BOTTOM OF CONSTANT SLOPE FOR UNLMITED WIND DURATION AND $\mathrm{f} / \mathrm{m}=10.6$ : PRESENTED AS DIMENSIONLESS PARAMETERS 


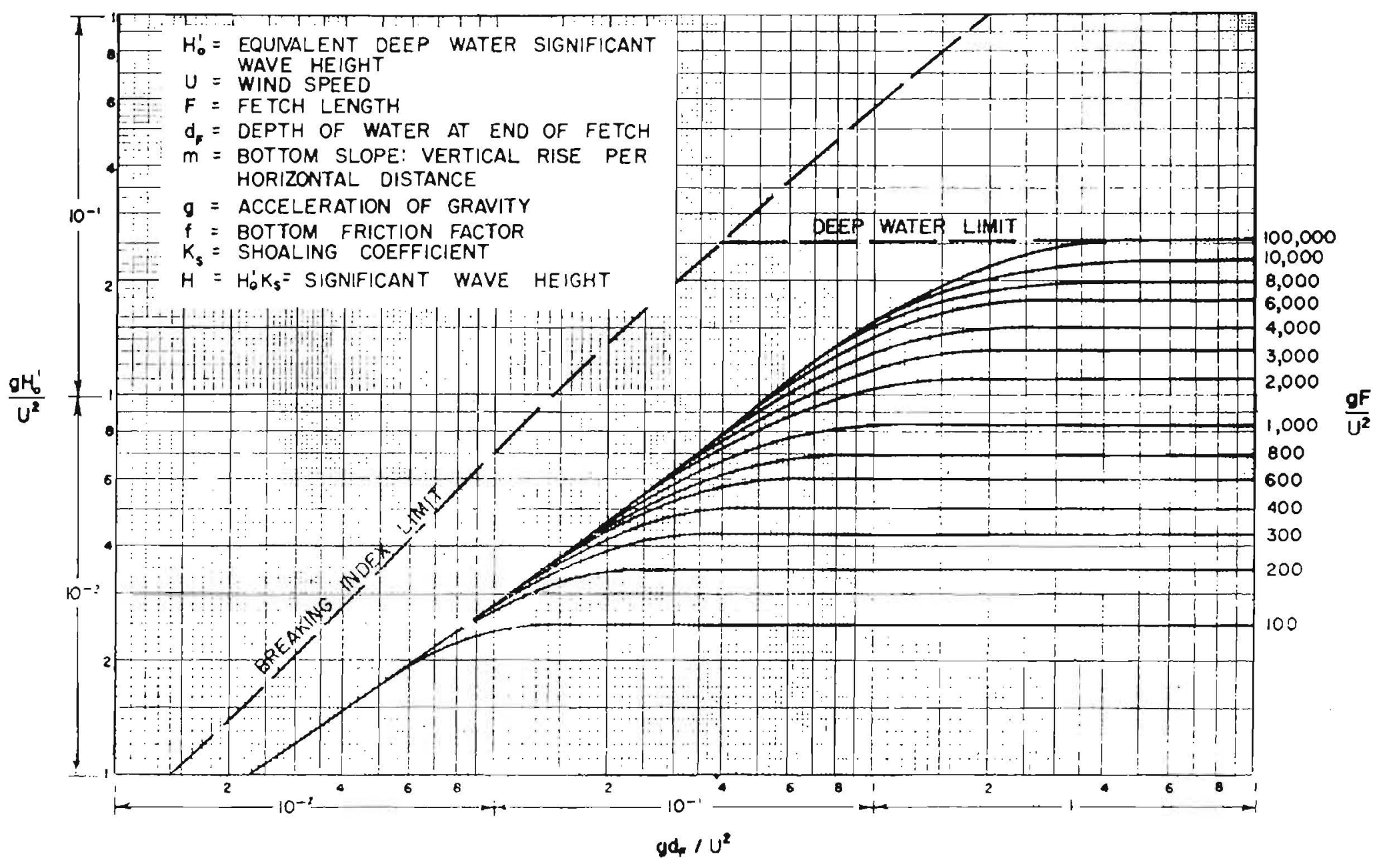

GENERATION OF WIND WAVES OVER A BOTTOM OF CONSTANT SLOPE FOR UNLIMITED WIND DURATION AND $f / m=52.8$ : PRESENTED AS DIMENSIONLESS PARAMETERS

FIGURE I! 


$$
\begin{aligned}
& \frac{g d F}{U^{2}}=\frac{32.2 \times 50}{(73.2)^{2}}=0.29 \\
& \frac{g_{0}^{\prime}}{U^{2}}=0.11 \\
& H_{O}^{\prime}=19 \text { feet } \quad \text { Figure } 10 \\
& \text { at } \frac{g H_{O}^{\prime}}{U^{2}}=\frac{g H_{O}}{U^{2}}=0.11, \frac{g F}{U^{2}}=2000 \text { Figure } 1 \\
& \text { at } \frac{g^{\prime}}{U^{2}}=2000, \frac{g T}{U}=4.0=\frac{\text { gT' }}{U} \text { Figure } 1
\end{aligned}
$$$$
T^{\prime}=9.1 \text { seconds equivalent deep water significant wave period }
$$$$
\mathrm{d} / \mathrm{L}_{\mathrm{O}}=50 \div 5.12(9.1)^{2}=0.118
$$$$
K_{S}=H / H_{O}^{\prime}=0.921 \quad \text { (Tables by wiegel) }
$$$$
H=19 \times 0.921=17.5 \text { feet, significant wave height at }
$$$$
d_{F}=50 \text { feet for } F=300 \text { miles, } U=50 \mathrm{mph} \text {. and } \mathrm{f} / \mathrm{m}=10.6
$$

The relationships presented in Figures 6 through 11 apply only to an impermeable bottom of constant slope. In cases of a permeable bot,tom one must consider percolation loss. The following equation for percolation loss over a permeable bottom of constant slope is obtained from reference (3).

where

$$
H=H_{O} K_{S}\left[\tanh \frac{2 \pi d}{L}\right]^{B}
$$

$$
B=\frac{8 \pi p}{u m T} \text {. The symbols are the same as given in }
$$

equations 7 and 9 .

Case III: General - Generation of Wind Waves Over a Variable Bottom

$$
\text { Slope. }
$$

The numerical method of computing the generation of wind waves in shallow water, taking bottom friction, percolation andrefraction into account, can be extended to a variable bottom slope, such as exists in the Gulf of wexico. This is done by using an average bottom slope for each increment of $\Delta x$ over for which the computations are made. The method can be applied to downslope $(m<0)$ as well as upslope $(m>0)$. In case of a flat bottom $(m=0)$, the relationships for a bottom of constant depth must be used. 


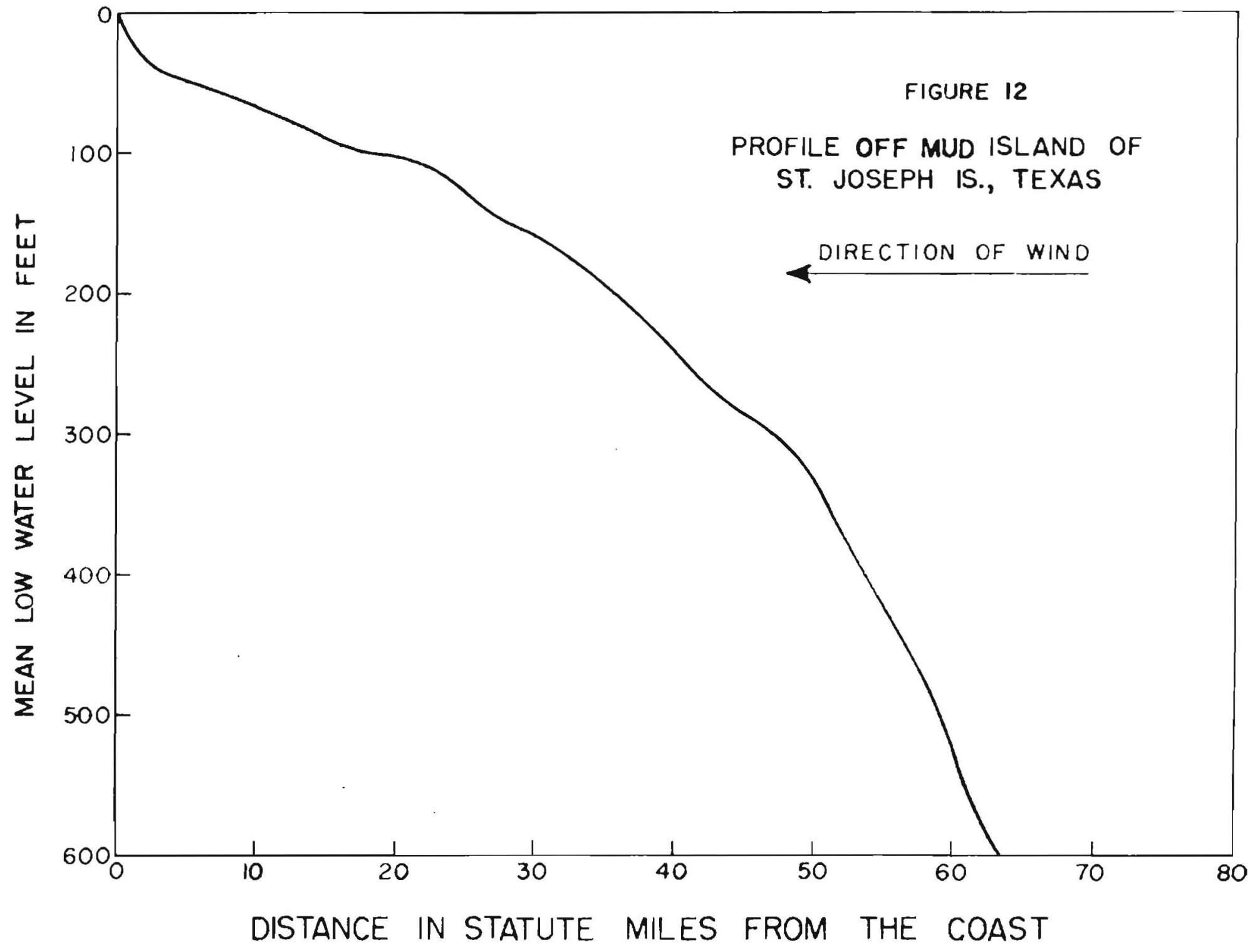




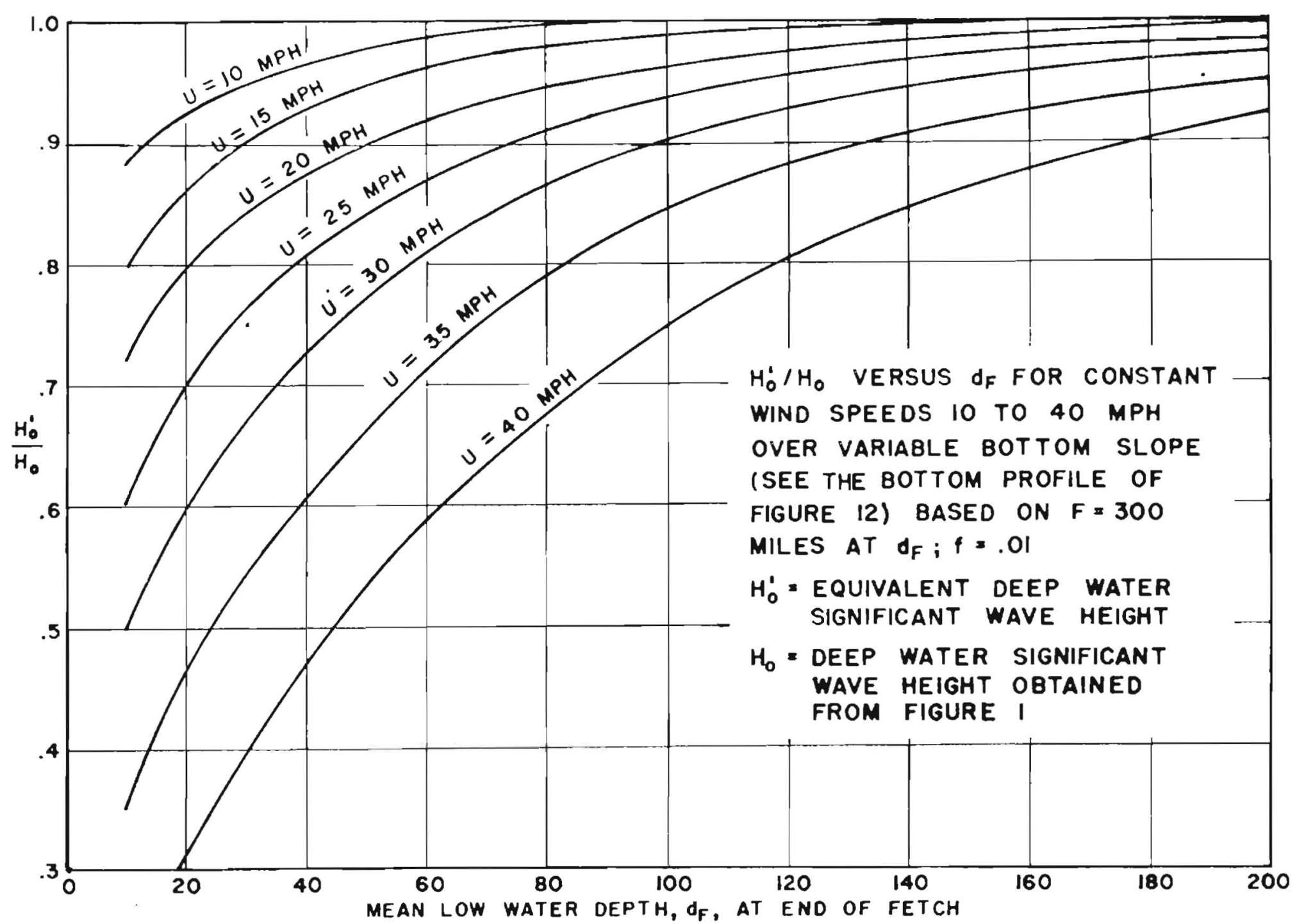

FIGURE I3 
Figure 12 is a typical bottom profile in the Gulf of Mexico off the South Texas coast. Using a bottom friction factor of $f=0.0 ?$ and a fetch length of 300 miles to any depth $d_{F}$, and assuming no percolation loss and no refraction, numerical computations were made for wind waves generated upslope over the bottom profile of Figure 12.

Figure 13 represents the results of these computations, which are given as $\mathrm{H}_{O}{ }^{\prime} / \mathrm{H}_{O}$ versus mean water depth, $d_{F}$, at end of $F=300$ miles. $\mathrm{H}_{\mathrm{O}}{ }^{\prime}$ is the equivalent deep water wave height based on numerical computations, taking bottom friction into account. $H_{O}$ is the actual deep water significant wave height that one would obtain by using Figure 1. A quick glance at Figure 13 clearly shows why the deep water wave forecasting relationships can not be used to predict waves on the continental shelf of the Gulf of Mexico. The square of the ratio of $\mathrm{H}_{\mathrm{O}} / / \mathrm{H}_{\mathrm{O}}$ is indicative of the error in wave energy that one would obtain by using the dsep water wave forecasting relationships, without considering bottom friction losses.

Figure 13 is only one example of the Gentral Case of wind generated waves over a variable sloping bottom. Each location and each direction for each location is a different problem. Percolation losses as well. as refraction effects should be investigated for each case. This, of course, requires detailed knowledge of the bottom configuration and soil conditions.

Summary and Conclusions. The method presented in this report is a first attempt in developing a set (or sets) of relationships which govern the generation of wind waves in shallow water, taking bottom friction and percolation into account.

The deep water wave forecasting relationships do not apply in shallow water and should not be used to predict wind waves in shallow water recions, such as the continental shelf of the Gulf of Mexico. Some estimate should be made of the bottom friction factor and permeability coefficient and computations of wave heights and periods should include energy loss due to bottom friction and percolation.

It is necessary to obtain empirical data on wind generated waves in shallow water for different bottom conditions. This would lead to a more accurate selection of the bottom friction factor to be used in the computations of wind generated waves in shallow water.

Acknowledgements. The author wishes to extend his appreciation to the following project personnel who helped with the material presented in this report: Mrs. Sue B. Cook, Messrs. Rudolph P. Savàge, Thomas J. Hopkins, and Roy D. Gaul.

Appreciation is also extended to personnel of the Jacksonville vistrict, U. S. Corps of Engineers, who made it possible to extend this study to include the revised relationships of wind-wave generation in shallow water. 


\section{List of References}

1. Arthur, R. S. "Revised Wave Forecasting Graphs and Procedure", Scripps Institution of Oceanography, Wave Report No. 73, 1947, U4 pp.

2. Bretschneider, C. I. "The Generation and Decay of Wind Waves in Deep Water", Transactions, A. G. U., Vol. 33, June 1953, pp. $381-389$.

3. Bretschneider, C. L., and Reid, R. O., "Change in Wave Height due to Bottom Friction, Percolation and Refraction", 34th Annual Meeting of American Geophysical Union, May 1953 (unpub.)

4. Putnam, J. A., and Johnson, J. W., "The Dissipation of Wave Energy by Bottom Friction", Transactions, A. G. U.,. Vol. 30, No.1 February 1949, pp. 67-74.

5. Putnam, J. A., "Loss of Wave Energy Due to Percolation in a Permeable Sea Bottom", Transactions, A. G. U., Vol. 30, No.3 June 1949, pp. 349-357.

6. Sverdrup, H. U., and Munk, W. H., "Wind, Sea, and Swell: Theory of Relationships for Forecasting", H. O. Pub. No. 601, U. S. Navy Dept., March 1948, 47 pp.

7. Wiegel, R. L., "Tables of the Functions of $d / L$ and $d / L_{0}$ ", Technical Report No. H. E. -116-265, Department of Engineering, University of Galifornia, Berkeley, January 1948, $58 \mathrm{pp}$.

8. Corps of Engineers, U. S. Army, "Hurricane Data", October 17-18, 1950", Proj. Bul. No. 5 (Project CW-167: Taves and Wind Tides in Inland Waters: Lake Okeechobee, Florida), Office of the District Engineer, Jacksonville, June 15, 1950.

9. Corps of Engineers, U. S. Army, "Hurricane Data, August 26-27, 1949", Proj. Bul. No. 2 (Project CW-167: Waves and Wind Tides in Inland Vaters; Lake Okeechobee, Floride) Office of the District Engineer, Jacksonville, June 15, 1950.

10. Bretschneider, C. L., "Wind Waves and Set-Up in Shallow Water, with Special Application to Lake Okeechobee", Tech. Report to Jacksonville District, Corps of Engineers, U. S. Army, August 1954 . 